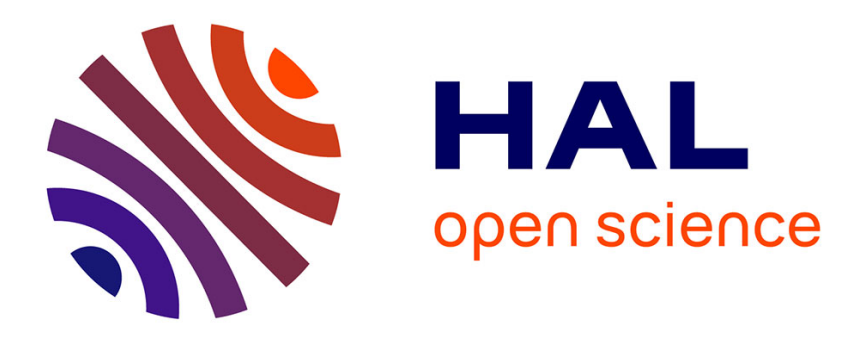

\title{
Characterization of porous silicon by positron annihilation
}

\author{
Y. Itoh, H. Murakami, A. Kinoshita
}

\section{To cite this version:}

Y. Itoh, H. Murakami, A. Kinoshita. Characterization of porous silicon by positron annihilation. Journal de Physique IV Proceedings, 1993, 03 (C4), pp.C4-193-C4-195. 10.1051/jp4:1993426 . jpa00251469

\section{HAL Id: jpa-00251469 https://hal.science/jpa-00251469}

Submitted on 1 Jan 1993

HAL is a multi-disciplinary open access archive for the deposit and dissemination of scientific research documents, whether they are published or not. The documents may come from teaching and research institutions in France or abroad, or from public or private research centers.
L'archive ouverte pluridisciplinaire HAL, est destinée au dépôt et à la diffusion de documents scientifiques de niveau recherche, publiés ou non, émanant des établissements d'enseignement et de recherche français ou étrangers, des laboratoires publics ou privés. 


\title{
Characterization of porous silicon by positron annihilation
}

\author{
Y. ITOH, H. MURAKAMI* and A. KINOSHITA ${ }^{* *}$
}

The Institute of Physical and Chemical Research (RIKEN), Hirosawa, Wako-shi, Saitama 351-01, Japan

* Department of Physics, Faculty of Education, Tokyo Gakugei University, Koganei-shi, Tokyo 184, Japan

** Faculty of Science and Engineering, Tokyo Denki University, Hatoyama, Saitama 350-03, Japan

\begin{abstract}
Characterization of porous silicon was performed by means of positron annihilation. Three components of the positron lifetime were observed, one of which was extremely long. The Doppler-broadened spectrum was sharp compared with that of crystal silicon, and became even narrower in an applied magnetic field. These results show that the porous structure is the cause of positronium formation in porous silicon.
\end{abstract}

\section{Introduction}

Porous silicon is obtained by the anodization of a silicon crystal in hydrofluoric acid and consists of a dense network of fine pores. The physical and chemical properties of porous silicon have attracted strong attention as result of its photoluminescence phenomena/1/. The mechanism of the photoluminescence has been actively studied, while its utilization has been discussed as an optical device and a gas and humidity sensor. Positron annihilation spectroscopy is a powerful tool for the study of the physical and chemical properties of porous silicon. The porous silicon surface is covered by a Si-H layer/2/ and the study of this layer is interesting from a view point of positronium chemistry and surface science. Observation by high resolution transmission microscopy has shown that small single crystal silicon spheres are surrounded by oxide in the porous layer/3/. In addition, scanning tunneling microscopy and atomic force microscopy have revealed that the porous structure is partially covered by an amorphous surface layer $/ 4 \%$. The exact microstructure of porous silicon is however still not fully understood. We therefore expect that positronium annihilation, taking particular notice of the positronium yield, should reveal useful information regarding the atomic scale microstructure of porous silicon. 


\section{Experimental}

The silicon substrates used were boron-doped wafers of $1 \sim 2 \mathrm{ohm}-\mathrm{cm}$ and 17 23 ohm-cm with (100) surface. The layer formed by anodization could be classified into three groups, according to the anodization conditions, as shown in Fig. 1. The porous layer obtained in region 1 had good quality and was used in our study. In region 3 , electrolyte polishing was realized and region 2 forms a transition region between the formation of the porous layer and electrolyte polishing. The substrates were anodized in hydrofluoric acids of $20 \mathrm{wt} . \%-55$ wt. $\%$ at a constant current density ranging from $10 \mathrm{~mA} / \mathrm{cm}^{2}$ to $100 \mathrm{~mA} / \mathrm{cm}^{2}$ as indicated by the arrows in Fig. 1. The thickness of the porous layers ranged from $30 \mu \mathrm{m}$ to $100 \mu \mathrm{m}$. The porosity, which is defined as the ratio of the reduced mass of the anodized layer to its mass before the anodization, varied from 0.5 to 0. 7. Measurements of the positron lifetime and Doppler broadening were carried out on the anodized samples sandwiching a positron source of $22 \mathrm{NaCl}$ or $48 \mathrm{~V}$ produced by the reaction of $48 \mathrm{Ti}(\mathrm{p}, \mathrm{n})^{48 \mathrm{~V}}$. The positron lifetime was measured with a fast-fast coincidence system whose time resolution was 210 ps. The Doppler spectrum was obtained with the aid of a pure Ge detector with an energy resolution of $1.07 \mathrm{keV}$. The lifetime spectra were analyzed with the computer program POSITRONFIT/5/.

\section{Results and Discussion}

The typical characteristics of two porous silicon sample are shown in Table 1 .

Table 1. Comparison of lifetime and intensity in two kinds of porous silicon

\begin{tabular}{|c|c|c|c|c|c|c|c|}
\hline $\begin{array}{l}\text { Sample No. } \\
\text { (Resistivity) }\end{array}$ & $\begin{array}{l}\mathrm{HF} \\
(\%)\end{array}$ & $\begin{array}{l}\text { Current } \\
\left(\mathrm{mA} / \mathrm{cm}^{2}\right)\end{array}$ & $\begin{array}{l}\text { Thickness } \\
\qquad(\mu \mathrm{m})\end{array}$ & Porosity & $\begin{array}{l}\tau_{1}\left(1_{1}\right) \\
p s(\%)\end{array}$ & $\begin{array}{l}\tau_{2}\left(I_{2}\right) \\
\operatorname{ps}(\%)\end{array}$ & $\begin{array}{l}\tau_{3}\left(I_{3}\right) \\
p s(\%)\end{array}$ \\
\hline$A(\sim 2 \Omega \mathrm{cm})$ & 55 & 107 & 35 & 0.53 & $213(84)$ & $510(8)$ & $17300(8)$ \\
\hline$B(\sim 23 \Omega \mathrm{cm})$ & 46 & 102 & 33 & 0.55 & $233(88)$ & $1700(1)$ & $22800(8)$ \\
\hline
\end{tabular}

Three components of the positron lifetime were observed in the porous silicon. $\tau_{1}$ originated from the lifetime in the free state in the substrate crystal. $\tau_{2}$ may be characteristic of positronium physisorbed on a small void surface or a positron trapped on its surface. Although it is hard to determine from the lifetime measurement whether $\tau_{2}$ is attributed to physisorbed positronium or to the surface positron, this lifetime reveals that voids are formed in the porous layer. $\tau_{3}$ is extremely long and reveals that ortho-positronium is formed in the porous silicon. The Doppler spectrum of the porous silicon is sharp compared with that for the crystalline silicon and became even narrower in an applied magnetic field, 
as shown in Fig.2. This suggests para-positronium formation in the porous silicon and we conclude from these results that the porous structure is the cause of the positronium formation. It has recently been : reported that positronium formation occurs in hydrogenated amorphous silicon but that no formation occurs unhydrogenated amorphous silicon/6/. The present results suggest that some areas of the porous silicon, probably the void surfaces, have the same atomic structure as hydrogenated amorphous silicon. It is known that large amounts of absorbed hydrogen and terminate the surface dangling bonds of porous silicon during anodization in $\mathrm{HF}$ solution. In conclusion it has been shown that positron annihilation spectroscopy reveals much information on the microstructure of porous silicon made by different anodization conditions, such as HF concentration and current density.

\section{References}

/1/Canham, L. T., Appl. Phys. Lett., 57, (1990) 1046.

/2/Tsang, C., Appl. Phys. Lett. 60, (1992) 639.

13/Nishida, A., Nakagawa, K., Kakibayashi, H., and Shimada, T., Jpn J. Appl.

Phys., 31, (1992) L1219.

/4/Anisola, G. B., Behrensmeier, R., Galligan, J. M., Otter, F. A., Namavar, F., and Kalkoran, N. M., Appl. Phys. Lett. 61, (1992) 2595.

15/Kirkgaard, P., Eldrup, M., Mogensen, O. E, and Pedersen, N. J., Computer Physics Commun., 23, (1981) 307.

16/ Suzuki, R., Kobayashi, Y., Mikado,

T., Ohgaki, H., Chiwaki, M.,

Yamazaki, T., and Tomimasu, T.,

Mater. Sci. Forum, 105-110, (1992) 1459.

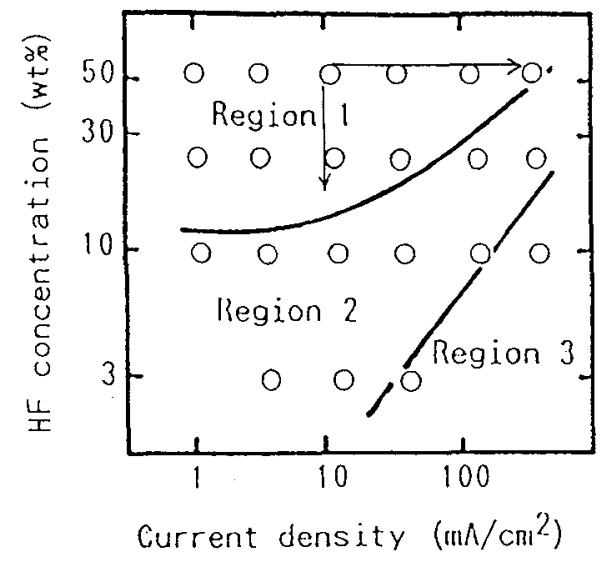

Fig. 1: Three groups of anodization condition.

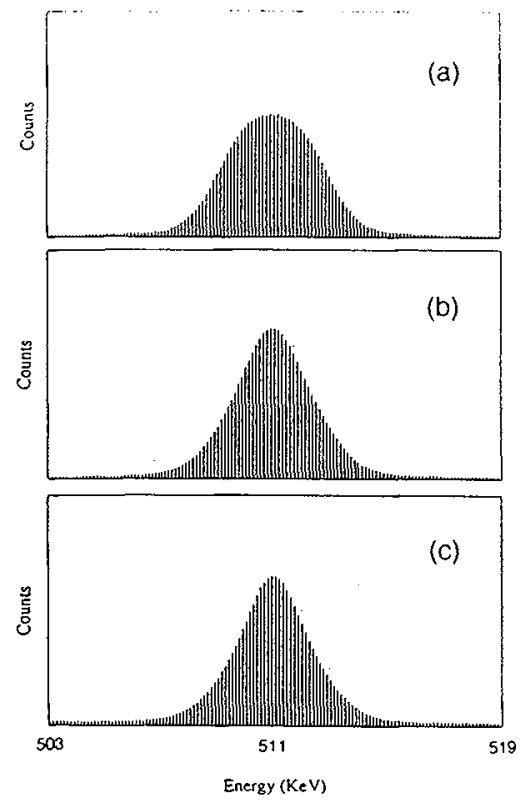

Fig.2: Doppler broadened Spectra of

(a) bulk silicon, (b) porous silicon $(\mathrm{B}=0)$ and (c) porous silicon $(B=0.3 T)$. 